\title{
Genitourinary Hydatid Disease: A Review
}

Sujatha Siddappa ${ }^{1^{*}}$ and Vilvapathy Senguttuvan Karthikeyan ${ }^{2}$

${ }^{1}$ Department of Pathology, Institute of Nephro Urology, Bangalore, India

${ }^{2}$ Postgraduate in Urology, Institute of Nephro Urology, Bangalore, India

*Corresponding author: Dr. Sujatha Siddappa, Associate Professor, Department of Pathology, Institute of Nephro Urology, Bangalore, India, Tel: 080-25530507; E-mail: dr.sujathasiddappa@gmail.com

Received date: February 25, 2016; Accepted date: April 07, 2016; Published date: April 12, 2016

Copyright: ( 2016 Siddappa S, et al. This is an open-access article distributed under the terms of the Creative Commons Attribution License, which permits unrestricted use, distribution, and reproduction in any medium, provided the original author and source are credited.

\section{Introduction}

Parasitism means a temporary or permanent reciprocal association between two species, where one species depends upon another for its existence. The most important parasitic diseases involving the genitourinary system in humans are helminthic, where schistosomiasis is the commonest followed by hydatid disease (HD) and filariasis [1]. $\mathrm{HD}$ is a parasitic infestation, caused by tape worms of the genus Echinococcus, that usually involves the liver and lungs, although no organ is spared $[2,3]$. The varied presentations and complications of $\mathrm{HD}$ present routine surgical problems in endemic areas, although HD of the urinary tract is uncommon, comprising $2-4 \%$ of all cases [3]. This article reviews the epidemiology, etiopathogenesis, clinical features and presentations, medical and surgical treatment of genitourinary and pelvic echinococcosis with special reference to individual organs. In addition our own experience at our hospital in the last 4 years that we treated 4 cases of hydatid cysts of which 3 were renal $\mathrm{HD}$ and one was primary pelvic HD.

Keywords: Genitourinary hydatid disease; Echinococcosis; Hydatid cyst

\section{Echinococcosis}

\section{Epidemiology}

The disease is caused when food and water that contains eggs of the parasite are eaten by or by close contact of the infected animal. The eggs are released in the stool of the meat eating animals that are infected by the parasite, commonly infected animal are dogs, foxes and wolves. For these animals to be infected they must eat the organs of an animal that contains sheep or rodents. E. granulosus is endemic in India, Middle East, Asia, Australia, Africa, especially northern parts like Tunisia, Southern Europe, South America and the Mediterranean countries, New Zealand and Alaska where sheep rearing and cattle rearing is common occupation. Reservoir of the disease is maintained by allowing dogs to have free access to ingest organs of infected animals, slaughter of animals from farms or villages and from communities that practice ritual sacrifice. The surgical incidence is 50 per 100,000 population [1]. We would like to end by saying that very few countries are considered to be completely free of E. granulosus, by virtue of change in occupational practices, nomadic migration of shepherds and their herds and various other incidental factors endemicity of the disease varies, there always will be emergence and re-emergence of the disease in certain countries with its ability to spread Echinococcosis is an infection caused by the larval stage of a cestode (tapeworm) called Echinococcus $[4,5]$. There are 3 species Echinococcus granulosus is the most common type world over, followed by E. multilocularis, E. oligartus and E. vogeli, the latter being popularly known as human polycystic hydatid disease [4-7].

\section{Organ of involvement}

The liver is the most commonly involved (45-75\%), followed by the lungs (10-50\%). Heart, spleen, kidney, and brain constitute only $10 \%$ of cases [8-12]. Genitourinary tract infestation is rare and kidneys are the most commonly affected, constituting for $1-5 \%$ of all cases $[10,12,13]$. Genitourinary hydatid (GUH) patients are usually asymptomatic on rupture of the cyst and are diagnosed many years later until being evaluated for other symptoms $[7,14]$. Adrenal gland is involved in less than $1 \%$ cases. $[15,16]$ Pelvic echinococcosis (PE) is rare, with an incidence of $0.2-2.25 \%$ and retrovesical location is even rarer $[10,11,17-19]$. Bladder, prostate and even testis have been reported as sites for HD.[7] Hydatid cysts (HC) in the peritoneal cavity or pelvis are usually a result of spontaneous rupture from a primary liver focus or following surgical inoculation [10,20]. Pelvic and retrovesical locations are considered primary if no other site is affected $[6,10,12,21]$. Mostly pelvic HC coexist with hepatic HC, detected before or on simultaneously, hence most of these cysts are secondary $[10,12,22]$. Retrovesical echinococcosis accounts for only $0.1-0.5 \%$ and $1-2 \%$ in a Tunisian series [12,23-26]. Most retrovesical HC have been reported from Turkey [6]. Approximately $80 \%$ of PE involves the genital area. Ovary is the most frequent location, followed by uterus [27]. In primary PE, the disease is exclusively confined to genital organs and inoculation is hematogenous [28].

\section{Life cycle}

$\mathrm{HD}$ is an anthropozoonosis caused by the larval stage of the different types of Echinococcus $[1,10,26]$. The adult tapeworm resides in the dogs' small intestine, attached to the villi of ileum [4]. Carnivores such as dogs, wolves, and foxes are the definitive hosts [4,7,29-31]. Adult worms mature in the small intestine of these definitive hosts and shed their proglottids in feces [7]. Eggs are passed and deposited within the dogs' feces $[3,7,10]$. Herbivores such as sheep, horses, cattle, pigs, goats, camel, and humans (accidental dead end hosts) are intermediate hosts [4,7]. They ingest eggs excreted in the dogs' feces $[4,10,29,30]$. Eggs penetrate the duodenum and enter the portal system [31]. Oncosphere larvae are released in small intestine and penetrate the mucosa to reach the lamina propria [7]. Liver and lungs act as first and second filters for the embryos respectively [30]. Only a few embryos not filtered out escape into the systemic circulation and passive transport to target organs occurs by haematogenous or lymphatic route [4,7]. Embryos not destroyed by phagocytosis develop into HC (Greek: hydatisa means a drop of water) $[4,30,32]$. Usually patients are asymptomatic for years. In the human duodenum, the parasitic embryo penetrates the mucosa, allowing 
Page 2 of 8

access to the blood stream, and enters the liver (most commonly) and the lungs $[4,5]$. The trilayered cyst consists of an inner germinal layer giving rise to protoscoleces, middle a cellular laminated layer and an outermost host derived fibrous layer [7]. The life cycle is depicted in Figure 1. Clinical HD in man occurs following the development of HC. Eradication of the disease needs breaking this life cycle, by avoiding access for dogs to untreated offal, especially from sheep. Though sounds easy, public health education is often misunderstood and only slow progress is achievable. Treating dogs for this infection has been proposed as a reliable alternative $[1,7]$.

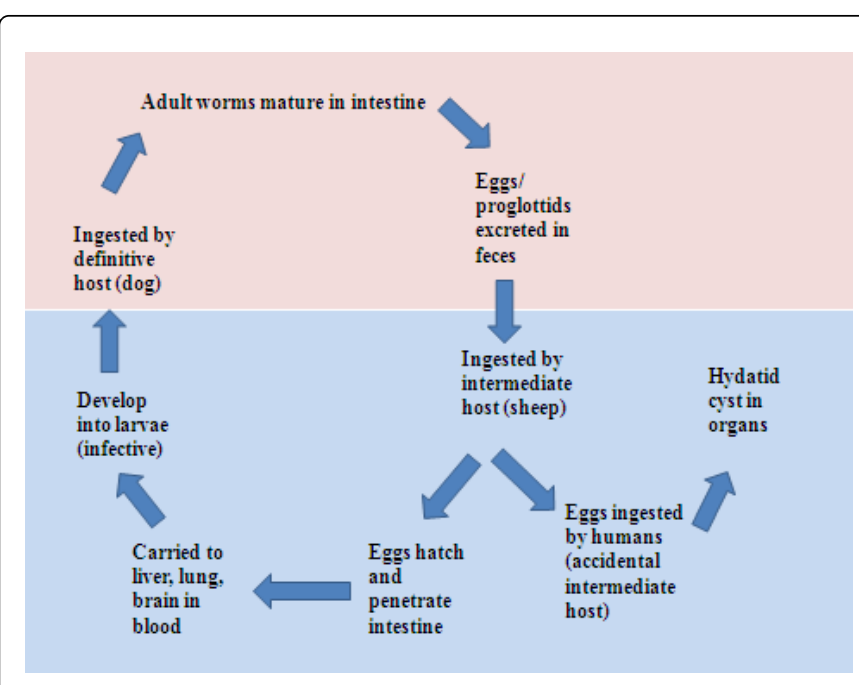

Figure 1: The life cycle of the worm.

\section{Clinical Features}

Clinical manifestations result from haematogenous invasion of the liver and the lungs [4]. HCs are typically slow growing, taking 5-20 years to grow into symptomatic sizes $(3-15 \mathrm{~cm})$ and clinical presentation seldom suggests diagnosis [4,5,7,33]. Most common symptoms of renal echinococcosis are palpable mass, flank pain, hematuria, malaise, and fever [34]. Hydatiduria, characterized by passing grape-like material in the urine resulting from the rupture of the cysts into the collecting system is pathognomonic. But has been reported only in $5-25 \%$ cases $[4,34]$. Adrenal masses cause flank pain and hypertension $[7,8]$. There are no specific symptoms of pelvic HD. The mode of presentation is determined by the size of the cyst and complications. HD is very rare in pregnancy but has been reported to cause obstructed labor due to left adnexal hydatidosis [26]. Retrovesical hydatidosis present with lower urinary tract symptoms, acute urinary retention, suprapubic mass, chronic renal failure and unilateral non-functioning kidney [10,35-40].

\section{Diagnosis}

\section{Imaging}

Imaging plays a key role in the diagnosis and staging of $\mathrm{HD}$ [4,7,41-43]. Plain abdominal radiography may reveal ring-shaped, linear, multilaminated, or amorphous calcifications. Intravenous urography shows distortion of the calyces or caliectasis due to renal mass involving the pelvi-calyceal system $[1,4]$. Rarely it may show up a nonfunctioning kidney or a filling defect in the renal pelvis $[4,44]$.
Preoperative diagnostic accuracy has been found to be $74 \%$ for ultrasound (US), 87.5\% for computed tomography (CT) and $73.3 \%$ for serological tests $[7,13]$. US demonstrates site, size and number of cysts, unilocular or multivesicular nature, floating membranes, daughter cysts, and hydatid sand. Transrectal US is helpful in evaluating pelvic cystic lesions [4,7]. US picture of HC is homogenous, multicystic, hypoechoic mass with septations (Figure 2) [1,7]. US is mainly to specify the location of the cyst, its vascular relations, and the existence at other locations $[12,23,25]$. Type 1 is the monovesicular simple cyst [12].

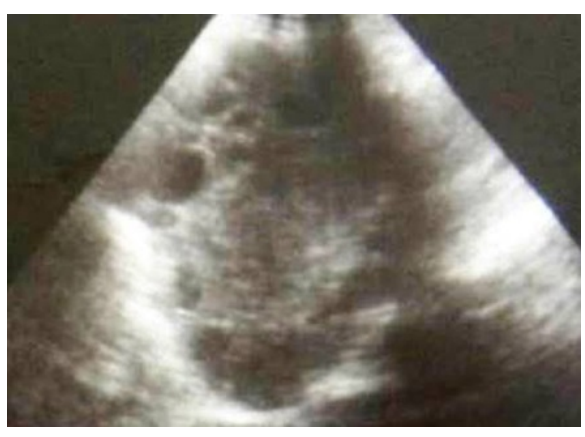

Figure 2: Ultrasound showing retrovesical hydatid cyst.

Hydatid may be classified into five types based on imaging classification of Gharbi et al. [12,45-49] Types 2, 3 and 5 do not pose a diagnostic problem, but type 4 called pseudo tumoral, can cause confusion [12].

T1 - pure fluid collection - non-complicated unilocular cyst.

T2 - fluid collection with a split wall- cyst with floating detached endocyst membrane.

T3 - cyst with septations and daughter cysts with predominant fluid on imaging.

T4 - cyst with predominant heterogeneous solid pattern with thick membranes and few daughter cysts.

T5 - calcified cyst with thick reflecting walls - non viable degenerated involuted cyst.

\section{WHO/IWG-E classification [7,45]}

This has been developed for diagnosis and treatment based on US imaging characteristics into 6 subtypes (CL, CE1 to CE5) and into 3 groups: active (CE1 and 2), transitional (CE3), and inactive (CE4 and 5) $[7,13]$.

CL - univesicular, cystic with uniform echoes, clear boundary, thin visible wall.

CE1 - univesicular anechoic cyst with hydatid sand, double wall, and snowflake sign.

CE2 - multi-vesicular, multi-septated cysts, producing "wheel-like" structures, and the presence of daughter cysts is indicated by "rosettelike" appearance.

CE3a - detachment of laminated membrane from the cyst wall, depicted as'big snake sign' or 'water-lily sign. This disease status is transitional. 
Page 3 of 8

CE3b - intracystic shadow of the daughter vesicles and solid septation, manifesting as complex cyst shadow.

CE4 - heterogenous, hypoechoic, or hyperechoic contents.

CE5 - intracystic solid degeneration and calcification of the cystic wall.

CT scan depicts HC as thick-walled cystic masses in kidney with typical peripheral location giving the so-called rosette appearance (Figure 3) [1]. CT has its own advantages in that it can detect calcification and daughter cysts much easily; It is more sensitive and accurate than US $[4,44]$. Stable, asymptomatic, and calcified cysts do not require specific therapy, however should be monitored with serial imaging over several years to ensure that they are benign [4]. Uni- or multilocular cystic lesions are identified with calcified walls, debris, small daughter cysts, and increased tissue density of hydatid membrane enhances on intravenous contrast [7,50]. Plaque-like calcifications in the cystic wall or the presence of daughter cysts by CT aids in diagnosis and sensitivity of CT ranges from 90 - 98\% [10,51,52]. CT scan provides additional information regarding the organ of origin, residual parenchyma in the affected organ and relationship of cyst to adjacent structures which is essential for planning the surgical approach and type. CT-guided diagnostic needle aspiration is contraindicated when echinococcosis is suspected due to risk of dissemination and anaphylactic reaction [7].

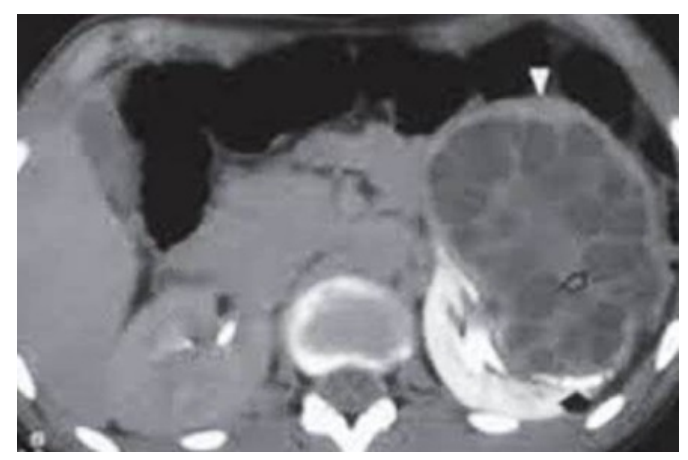

Figure 3: CT abdomen showing left renal hydatid disease.

Retrograde pyelography may not demonstrate communication with the pelvicalyceal system initially due to high intracystic pressures, but becomes apparent as soon as cyst is decompressed [7,53]. Magnetic resonance imaging (MRI) provides better tissue delineation especially in pelvic HD. HC must be considered in the differential diagnosis of cystic masses of the genitourinary tract as they radiologically and clinically mimic benign or malignant tumors and other cystic lesions of genitourinary tract, especially in endemic areas [7]. The cyst appears as a circumscribed mass with hypo intensity on T1, hyper intensity on T2 and changes little or not at all with contrast administration [12]. Daughter cysts with septa hypointensity on $\mathrm{T} 1$ and $\mathrm{T} 2$ sequences is pathognomonic of HD [23].

\section{Microbiological diagnosis}

There is no pathognomonic serological and immunological test and this is the reason for constant evolution of serological tests over time; however all have low sensitivity $[4,54]$. Eosinophilia is seen in $20-50 \%$ of patients, however this may be seen in any parasitic infestation $[4,55]$. Nonspecific and traditional tests like Casoni intradermal test, complement fixation tests, indirect hem agglutination and latex agglutination tests have been now replaced by Enzyme linked Immunosorbent assay (ELISA), immunoelectrophoresis, indirect immunofluorescence antibody test, and immunoblotting [7,56,57]. ELISA has positive titres in up to $80 \%$ of the cases.[58] Dipstick assays with nearly $100 \%$ sensitivity and approximately $91 \%$ specificity have been developed [59]. Cross reactions have been noted especially with anti-Cysticercus antibodies and serology must not be taken as the sole diagnostic criterion [1]. The newer immunodiagnostic tests are based on detection of Echinococcus antigens in the hydatid fluid, including E. granulosus antigen B (AgB), E. granulosus antigen 5 and EpC1. $\mathrm{AgB} 8 / 2$ antigen has the highest diagnostic sensitivity (84-93.1\%) and specificity (98-99.5\%) [7,60,61]. Serology has a definite role in follow up as the titres should fall after definitive and successful treatment [62].

\section{Treatment}

Treatment depends on the disease activity and symptoms. Active or symptomatic cysts need to be treated. Available treatment modalities include medical therapy, percutaneous intervention, and open or minimally invasive surgery or even robotic assisted surgeries in the modern era. Surgical excision provides the best cure [7].

\section{Medical therapy}

Medical therapy is used as an adjunct to surgical excision or as primary therapy in poor surgical candidates, disseminated echinococcosis [7,50]. Trials have shown the efficacy of the benzimidazole compound albendazole [1,63-65]. Preoperative therapy with albendazole (10-15 $\mathrm{mg} / \mathrm{kg}$ per day) with or without praziquantel $(50 \mathrm{mg} / \mathrm{kg}$ ) for 4 weeks before surgery kills the scolices, decreases cyst antigenicity, renders the cyst inactive, reduces cyst wall tension and reduces the risk of intraoperative spillage $[7,66]$. Cysts become smaller, osmotic pressure falls and it becomes softer and floppier and cyst membrane may separate. To achieve this benefit, treatment is needed for many months and the patient needs to be monitored for the possible hepatotoxicity [1]. In hepatic echinococcosis, only $4.16 \%$ receiving albendazole recurred while against $18.75 \%$ in those not receiving it $[7,67]$. However, a major limitation of medical therapy is the serious drug related adverse effect like hepatotoxicity, leukopenia, allergic reactions, and alopecia.[68] Unfortunately when chronic treatment is discontinued the disease may slowly regain its vigour and recur $[1,65,69]$. Though albendazole can penetrate the intact cyst effectively to achieve cyst fluid levels, it is a relatively weak antihelminthic. Praziquantel is a stronger agent available during surgery [1].

Praziquantel at $40 \mathrm{mg} / \mathrm{kg} / \mathrm{day}, 1-2$ weeks postoperatively will work well to eradicate infective particles spilled or released into the circulation [1]. However, it does not penetrate intact cysts. The ideal medical treatment is preoperative albendazole for 3 months or longer and praziquantel in the postoperative period for 2 weeks. Intraoperatively, hydrocortisone is used to avoid serious allergic reactions [1]. Stronger chemicals like $0.5 \%$ silver nitrate or $2.5 \%$ formalin, can be instilled directly into cysts after puncture $[1,54,55,65,69]$. Exposure of the germinal membrane to these agents will sterilize the cyst in 1-2 minutes [1]. 


\section{Surgery}

When technically feasible, active, expanding, symptomatic, and infected cysts are best treated with surgical excision or cyst aspiration with instillation of scolicidal agents [4,7]. Laparoscopy and robotics and image guided percutaneous techniques have decreased the morbidity associated with the conventional open surgical excision [7].

The objective is to remove all infective elements with no contamination or spillage and the goal of surgery is total cyst excision without spillage or contamination of the operative field (Figure 4) $[1,12]$ Whenever possible, the cyst should be excised, if necessary, along with some normal tissue such as partial nephrectomy or nephron-sparing pericystectomy [1,70-72]. Nephrectomy is reserved for destroyed kidneys (Figure 5) [70]. Small, asymptomatic cysts with wall calcification need no treatment [69]. The surrounding tissue must be protected by covering with pads soaked in scolicidal solutions and care must be taken to ensure that no spillage occurs, to prevent seeding and secondary infestation [1]. Scolicidal agents used include $30 \%$ sodium chloride, $10 \%$ povidone iodine, $0.5 \%$ silver nitrate, or $95 \%$ ethanol $[7,55,66]$. During surgery, the cysts should be packed on all sides with gauzes soaked in scolicidal solutions like $20 \%$ normal saline solution, $1 \%$ iodine, $10 \%$ cetrimide, $10 \%$ povidone-iodine, or $0.5 \%$ silver nitrate $[7,73]$. Laparoscopic evacuation of the HC with excision of the redundant cyst and pericyst tissue has been reported. With advances in interventional radiology, percutaneous drainage is also being done $[1,74]$. Both these treatment modalities have reported successful outcomes at short-term follow-up [74]. Recurrent cysts caused by seeding during any of these minimally invasive procedures usually become evident only beyond 5 years, hence long-term followup is necessary [1].

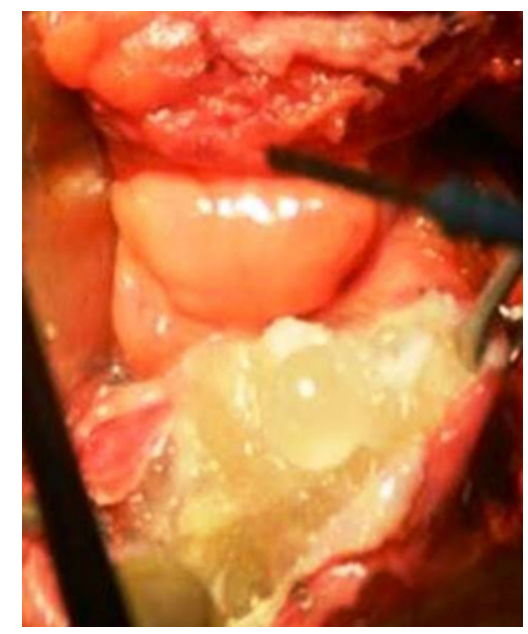

Figure 4: Intraoperative image showing hydatid cyst and multiple daughter cysts.

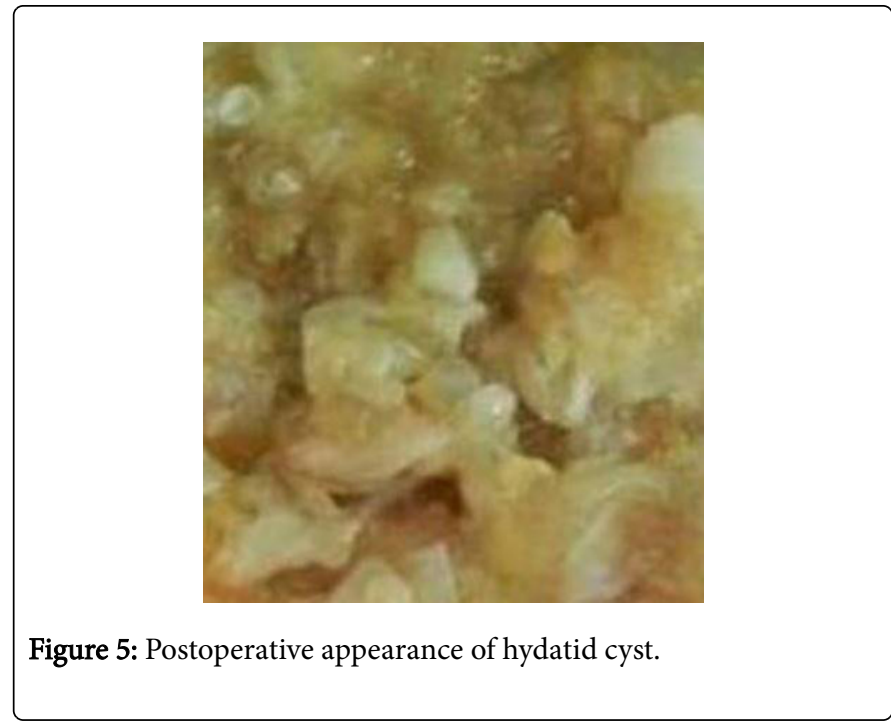

\section{Approach}

Some authors recommend extra peritoneal approach to minimize the risk of intraperitoenal hydatid dissemination [12,75-77]. Midline laparotomy is recommended whenever the diagnosis is in doubt or there is an associated intraperitoneal cyst [10,75]. This technique involves injection of a scolicidal solution (hypertonic saline or hydrogen peroxide) for 10 minutes and draining the cyst [12]. If the $\mathrm{HC}$ is infected, it is advisable to instill an irrigation-drainage system to prevent secondary collections and intraperitoneal dissemination [75]. Traditional surgery is associated with a wide range of complications and with the development of minimally invasive managements; morbidity has been minimized [12]. Smaller incision leads to less postoperative pain, and wound-related complications [7]. The anesthetist should be ready with epinephrine injections as severe anaphylactic reactions are known [73]. Trans peritoneal and retroperitoneal laparoscopic approaches have been described [78]. Trans peritoneal approach provides a larger working space outside the Gerota fascia and this prevents inadvertent cyst rupture [79].

\section{Percutaneous aspiration, instillation and re-aspiration (PAIR)}

PAIR under US has been devised to reduce the morbidity associated with open surgical procedures in cases of unilocular cysts with no communication with the collecting system, but carries the risk of dissemination of daughter cysts. Lethal anaphylaxis has been reported in $0.03-0.04 \%$ procedures $[7,80]$.

\section{Palanivelu hydatid system (PHS)}

PHS primarily described in hepatobilliary HCs, aids in controlled removal of internal contents and endocyst without excising the entire cyst laparoscopically with minimal fear of intraperitoneal spillage [81]. It has a $12 \mathrm{~mm}$ trocar and cannula assembly with 5 and $8 \mathrm{~mm}$ reducers and $26 \mathrm{~cm}$ long cannula with $12 \mathrm{~mm}$ inner diameter with suction and irrigation channels. The pyramidal tip of the trocar has fenestrations. Shaft is hollow to accommodate the suction cannula. This design allows easy suction of scolices and avoids spillage of contents. After aspiration, the cannula can be used for visualization of intracystic architecture and to rule out its communication with the collecting 
system. Scolicidal agents can be aspirated after 10 minutes contact time. The residual cyst can then be marsupialized or excised depending on the location and specimen is retrieved through a retrieval bag [81].

Retroperitoneoscopy further minimizes the risk of intraperitoneal spillage of cyst contents [82]. Through standard three-port $(5,10,10$ $\mathrm{mm}$ ) retroperitoneal access at 90-degree flank position, with balloon dilatation, cyst wall is packed with gauze soaked in scolicidal agent. Ozden et al. described a purse-string suture on the cyst wall followed by cyst perforation with hook dissector, aspiration of fluid contents, Then followed by the instillation of scolicidal agent. After this cystopericystectomy is done with removal of intact cyst could be removed [82].

\section{Specific Organs}

\section{Renal echinococcosis (RE)}

$\mathrm{RE}$ is very rare, caused by the larval stage of E. granulosus. Patient presents with flank pain or abdominal mass, hematuria, malaise, and fever $[1,7,46,47,71,83]$. RE presents between the third and fifth decades of life, accounting for $2-3 \%$ cases $[7,84]$. Left renal involvement is more common than the right probably owing to the smaller renal artery $[7,13]$. Surgical treatment planning for RE is based on degree of renal involvement and residual renal function, size, location and number. Surgical treatment options for RE include cysto-pericystectomy, cyst reroofing with endocyst evacuation, and partial (PN) or total nephrectomy. Laparoscopic management of renal $\mathrm{HC}$ was started in 1991 [53]. Nephrectomy should be avoided considering the benign nature of the disease and that it can recur. Ex-vivo surgery with orthotopic reimplantation has been reported for a centrally located HC with good short-term outcome [85]. PN is indicated for thickened or calcified cysts especially when diagnosis is doubtful [7,50]. Nephronsparing surgeries (NSS) can be completed in $75 \%$ cases $[57,86]$. Nephrectomy is needed only in cases where the entire kidney is replaced by a $\mathrm{HC}$ or in poorly functioning kidney, cyst haemorrhage or infection, or communicating cysts (Figure 6) [50]. Two main challenges in minimal invasive surgery for RE include the risk of intraperitoneal spillage and difficult evacuation of particulate cyst contents. Giant multilocular renal HCs have been successfully treated by Santosh-PGI technique which involves percutaneous nephroscopic aspiration, instillation, and re-aspiration through single periumbilical incision laparoscopic approach [53]. After pneumoperitoneum, three conventional laparoscopic trocars with cannula (one $10 \mathrm{~mm}$ and two 5 $\mathrm{mm}$ ) are inserted through periumbilical incision. Cyst is punctured after colon mobilisation, with an $18 \mathrm{G}$ puncture needle introduced through the right lumbar region. Scolicidal $10 \%$ povidone-iodine is instilled for 10 minutes, followed by the passage of Terumo guide wire and the tract is dilated to $30 \mathrm{~F}$. Two separate camera monitors are used: one for laparoscopy and the other for HC cystoscopy. Suction catheter through the $5 \mathrm{~F}$ periumbilical port sucks out spilled fluid during tract dilatation. Following dilatation, a $24 \mathrm{~F}$ rigid nephroscope is introduced into cyst and the contents are aspirated under vision followed by the removal of the laminated membrane with grasping forceps (Figure 7). This attractive technique has acceptable success rates with reduced morbidity and highlights the feasibility of successful laparoscopic treatment even in giant HC [53]. Laparoscopic guidance prevents colonic injury. It is cost effective and cosmetically appealing.

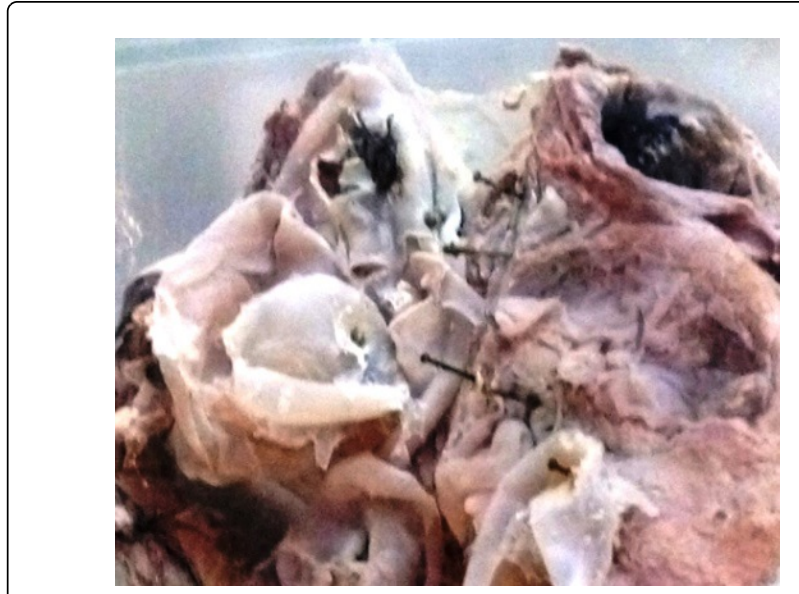

Figure 6: Gross specimen showing left nephrectomy specimen with daughter cysts.

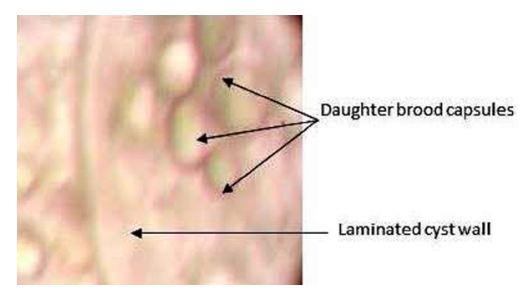

Figure 7: Photomicrograph. Wet mount (100X) showing laminated cyst wall and daughter brood capsules.

\section{Adrenal hydatid cysts (AHC)}

Small and uncomplicated cysts are asymptomatic, however about $80 \%$ of AHC patients are symptomatic $[8,87]$. It accounts for $6-7 \%$ of all adrenal cysts $[7,15,16,66,88]$. Patients may present with hypertension, known as Goldblatt phenomenon, due to irritation of the functional tissue of the adrenal by growing cyst and is curable by cyst ablation $[8,89]$. Many authors believe adrenal involvement to be a part of a generalized echinococcosis [90,91]. Treatment of AHC is mainly total cyst excision. If cyst is large and adherent to vital structures, partial pericystectomy and adequate drainage of the remaining cystic cavity is acceptable. Total excision of AHC when adherent to the renal hilum can be disastrous. Laparoscopic adrenalectomy has been described with transperitoneal aspiration with instillation of scolicidal agent with partial cystectomy $[7,92]$.

\section{Pelvic echinococcosis (PE)}

Ovarian involvement is the commonest among PE. Symptomatology includes non-specific symptoms like abdominal pain, menstruation irregularities, infertility, and urinary disturbances [93]. Ovarian echinococcosis can mimic polycystic ovarian disease, malignancy or endometriosis $[94,95]$. It has been shown to cause obstructed labour requiring caesarean section [96]. Treatment is cyst excision or marsupialisation. Uterine echinococcosis has been described and they present with menorrhagia, may be misdiagnosed as molar pregnancy [97]. Primary broad ligament HC is extremely rare condition contributing to $0.037 \%$ of all cases and may be misdiagnosed 
Page 6 of 8

as pedunculated fibroid or paraovarian cyst $[98,99]$. Due to location within the narrow confines of the pelvis and dense adhesions to surrounding structures, excision is a formidable task. Laparoscopic excision of pelvic HC using PHS was reported by Subramaniam et al, allows a safe minimally invasive option to the existing surgical techniques $[7,12,100]$. Robot-assisted surgical excision of the pelvic $\mathrm{HC}$ has been reported. Superior magnification, 3D vision and endowrist help in accurate dissection with minimal damage to adjacent structures and aids in complete cyst excision [7].

\section{Bladder echinococcosis and retrovesical hydatidosis (RVH)}

Bladder echinococcosis is characterized by clinical latency [7]. Pelvic HC affecting the bladder occur in $5 \%$ cases. They may present with frequency of micturition, urgency, urinary retention or obstructive azoospermia [1,100]. Isolated RV cyst is a very rare diagnosis for a suprapubic mass presenting with lower urinary tract symptoms (LUTS) [30]. Pelvic RVH occurs by peritoneal dissemination, haematogenous or lymphatic seeding or spread from rectal mucosa to the perivesical and pelvic venous plexus [103]. Even in endemic regions, it accounts to only $2 \%$ of all genitourinary echinococcosis [31,102]. On initial imaging, it mimics rectal duplication cyst, recto sigmoid neoplasm, posterior bladder diverticula, seminal vesicle cyst or hydronephrosis in pelvic kidney $[30,105]$ When daughter cysts are seen on CT, it is diagnostic.[12] In female patients, RVH may mimic ovarian neoplasm, Mullerian remnant, hydrosalpinx, pseudomyxomaperitonei or tubal ectopic pregnancy [10]. Shailesh Chandra et al. reported for the first time, the use of the da Vinci surgical system for RVH [106]. RVH may contain small bowel, sigmoid colon, rectum, ureter, urinary bladder, pelvic vessels, or internal genital of females as part of pericyst. A high risk of inadvertent pelvic visceral injury exists. PHS has been successfully employed. Pelvic HC have also been excised transvaginally [108].

\section{Prostate hydatid cyst}

Prostatic involvement occurs by hematogenous dissemination and cyst develops in the prostatic stroma, presenting as intraprostatic cystic mass [7]. It may rupture into the urethra causing hydaturia and stone formation can occur due to urine stagnation in the remaining cystic cavity. Transurethral resection of the prostatic tissue separating the cystic cavity from urethra has been to produce good drainage with potentially no risk for stone recurrence [7,11]. Endoscopic and laparoscopic management of prostatic $\mathrm{HC}$ have been reported with application of similar therapeutic principles $[107,108]$.

\section{Other genitourinary sites of involvement}

Scrotal, testicular, epididymal, and seminal vesicle HC have been reported $[107,108]$. The blood-testis barrier has been attributed to testicular resistance to echinococcosis (testicular echinococcosis) $[42,108]$. It presents as testicular mass and diagnosis is made only on final histopathology of orchidectomy specimen. Orchidectomy is usually done for suspicion of testicular malignancy or tuberculosis [109]. It can be primary or secondary [110]. Seminal vesicles HC have been reported to cause LUTS [111].

\section{Conclusion}

Genitourinary echinococcosis is uncommon disease and preoperative diagnosis requires a high index of suspicion and especially considered in patients in endemic regions with cystic masses. Complete excision of germinal layer with daughter cysts without spillage of viable cyst contents with preoperative medical therapy is the gold standard and minimally invasive surgery is feasible with advantages of early recovery and minimal spillage due to availability of special devices. Follow up for recurrence and dissemination is essential.

\section{References}

1. Kehinde EO, Anim JT, Hira PR (2008) Parasites of urological importance. Urol Int 81: 1-13.

2. Shetty SD, al-Saigh A, Ibrahim AI, Patil KP, Bhattachan CL (1992) Management of hydatid cysts of the urinary tract. Br J Urol 70: 258-261.

3. Ozbey I, Aksoy Y, Polat O, Atmaca AF, Demirel A (2002) Clinical management of hydatid disease of the urinary tract. J Int Med Res 30: 346-352.

4. White AC Jr, Weller PF (2005) Helminthic infections. Cestodes. In: Kasper DL, Braunwald E, Fauci AS, Hauser SL, Longo DL, Jameson AL (eds) Harrison's principles of internal medicine. McGrow-Hill, New York pp. 1253-72.

5. Tuygun C, Bakirtas H, Imamoglu MA, Sertcelik N, Zengin K, et al. (2006) The unusual mass of retrovesical space: a secondary hydatid cyst disease. ScientificWorldJournal 6: 2481-2485.

6. Santosh Kumar, Shivanshu Singh (2015) Genitourinary Hydatid Disease. In: Alfonso Rodriguez-Morales (ed.) Current Topics in Echinococcosis. InTech Open, Croatia.

7. Kumar S, Nanjappa B, Gowda KK (2014) Laparoscopic management of a hydatid cyst of the adrenal gland. Korean J Urol 55: 493-495.

8. Kern P, Bardonnet K, Renner E, Auer H, Pawlowski Z, et al. (2003) European echinococcosis registry: human alveolar echinococcosis, Europe, 1982-2000. Emerg Infect Dis 9: 343-349.

9. Saadeh RJ, Mohamed AA (2011) Urinary retention: Unusual presentation of hydatid cyst. Case report and literature review. Int J Surg 27: 1-6.

10. Nouira Y, Binous MY, Nouira K, Mekni A, Kallel Y, et al. (2006) Intraprostatic hydatid cyst: an unusual presentation. ScientificWorldJournal 6: 2315-2318.

11. Saadi A, Bouzouita A, Cherif M, Rebai MH, Kerkeni W1, et al. (2015) Retrovesical hydatic cyst: About 4 cases. Can Urol Assoc J 9: E374-378.

12. Rexiati M, Mutalifu A, Azhati B, Wang W, Yang H, et al. (2014) Diagnosis and surgical treatment of renal hydatid disease: a retrospective analysis of 30 cases. PLoS One 9: e96602.

13. Emir L, Karabulut A, Balci U, Germiyanö̈Ÿlu C, Erol D (2000) An unusual cause of urinary retention: a primary retrovesical echinococcal cyst. Urology 56: 856.

14. Akçay MN, Akçay G, Balik AA, Böyük A (2004) Hydatid cysts of the adrenal gland: review of nine patients. World J Surg 28: 97-99.

15. Defechereux T, Sauvant J, Gramatica L, Puccini M, De Micco C, et al. (2000) Laparoscopic resection of an adrenal hydatid cyst. Eur J Surg 166: 900-902.

16. Aydogdu T, Gungor T, Tug M, Cavkaytar S (2006) Pelvic echinococcosis in differential diagnosis of pelvic massesEur J Obstet Gynecol Reprod Biol 129: 98-9.

17. Ozer T, Gundogdu S, Ozer Y, Mahmutyazicioglu K, Savranlar A, et al. (2004) Echinococcosis involving the liver, retrovesical and seminal vesicle presented with syncope. Int J Urol 11: 922-924.

18. Sethi SK, Solanki RS, Hemal U, Krishan S (2004) Unusual retrovesical location of hydatid cyst. Indian Journal of Radiology and Imaging 14: 104.

19. Kirkland K (1966) Urological aspects of hydatid disease. Br J Urol 38: 241-254.

20. Başaranoglu M, Sonsuz A, Perek A, Perek S, Akin P (1998) Primary pelvic hydatid cyst. J Clin Gastroenterol 26: 157-158.

21. Neagu V, Ioanid PC (1978) Juxtavesical hydatid cysts. Eur Urol 4: 111-114. 
22. Ben Ahmed Y, Khemekhem R, Nouira F, Boukedi A, Rahay H, et al. (2012) Retrovesical hydatic cyst in children: About four cases. Jpp 25: 131-5.

23. Hafsa C, Golli M, Kriaa S, Salem R, Jerbi Omezzine S, et al. (2007) [Retrovesical hydatid cyst in children: report of 3 cases]. J Radiol 88: 968-971.

24. Khouaja MK, Ben Sorba N, Haddad N, Mosbah AT (2004) [Retrovesical hydatid cyst: diagnosis and treatment in 8 cases]. Prog Urol 14: 489-492.

25. Ameur A, Boumadian H, Aqira A, Draoui D (1998) [Retrovesical hydatid cyst. Apropos of 6 cases]. Prog Urol 8: 557-560.

26. Ware SS, Patil SB, Sarate DS, Sawaitul VK (2015) Primary Pelvic Hydatid Cyst Obstructing the Labour. Journal of Krishna Institute of Medical Sciences 4: 127-130.

27. Zulfikaroglu E, Islimye M, Zulfikaroglu B, Danisman N (2010) Abdominal and pelvic hydatid cyst obstructing the labor. Bratisl Lek Listy 111: 464-466.

28. Choi H, Park JY, Kim JH, Moon du G, Lee JG, et al. (2014) Primary renal hydatid cyst: mis-interpretation as a renal malignancy. Korean J Parasitol 52: 295-298.

29. Sharma R, Bargotra R, Azad T, Singh M (2004) Hydatid cyst in rectovesical pouch. JK Sci 6: 101-2.

30. Gogus C, Safak M, Baltaci S, Turkolmez K (2003) Isolated rena hydatidosis: experience with 20 cases. J Urol 169: 186-189.

31. Horchani A, Nouira Y, Kbaier I, Attyaoui F, Zribi AS (2000) Hydatid cyst of the kidney. A report of 147 controlled cases. Eur Urol 38: 461-467.

32. Karabekios S, Gouliamos A, Kalovidouris A, Vlahos L, Papavasiliou C, et al. (1989) Features of computed tomography in hydatid cysts of the urinary tract. Br J Urol 64: 575-578.

33. Afsar H, Yagci F, Meto S, Aybasti N (1994) Hydatid disease of the kidney: evaluation and features of diagnostic procedures. J Urol 151: 567-570.

34. Bayraktar MR, Mehmet N, Durmaz R (2005) Th1 and Th2 inducing cytokines in Cystic echinococcosis. Turkiye Parazitol Derg 29: 167-170.

35. Dewangan M, Naik T, Mishra S, Singh RP (2015) Isolated retrovesical hydatid cyst presenting with obstructive uropathy and bilateral lower limb edema. Trop Gastroenterol 36: 60-62.

36. Nasr R, Saad GA, Shahait M, Khater N (2014) Retrovesical hydatid cyst presenting with urinary retention and left kidney atrophy. Urol Ann 6: 68-70.

37. Singh BP, Dhar DN (1988) Echinococcus granulosus in animals in northern India. Vet Parasitol 28: 261-266.

38. Yurdakul T, Piskin MM (2006) Pelvic hydatid disease causing renal failure. Journal of Ankara University Faculty of Medicine 59: 80-82.

39. Baijal SS, Basarge N, Srinadh ES, Mittal BR, Kumar A (1995) Percutaneous management of renal hydatidosis: a minimally invasive therapeutic option. J Urol 153: 1199-1201.

40. Brunetti E, Garcia HH, Junghanss T; International CE Workshop in Lima, Peru, 2009 (2011) Cystic echinococcosis: chronic, complex, and still neglected. PLoS Negl Trop Dis 5: e1146.

41. McManus DP, Zhang W, Li J, Bartley PB (2003) Echinococcosis. Lancet 362: 1295-1304

42. Angulo JC, Sanchez-Chapado M, Diego A, Escribano J, Tamayo JC, et al (1997) Renal echinococcosis: clinical study of 34 cases. J Urol 157: 787-794.

43. Atalar M (2013) Hydatid Cyst: A Pictorial Review of Radiological Appearances. Journal of Clinical and Analytical Medicine. J Clin Anal Med 4: 81-85.

44. Beggs I (1985) The radiology of hydatid disease. AJR Am J Roentgenol 145: 639-648.

45. Engin G, Acunas B, Rozanes I, Acunas G (2000) Hydatid disease with unusual localization. Eur Radiol 10: 1904-1912.

46. Pedrosa I, Saíz A, Arrazola J, Ferreirós J, Pedrosa CS (2000) Hydatid disease: radiologic and pathologic features and complications. Radiographics 20: 795-817.
47. Hassine W, Dupuch K, Gharbi HA (1980) [Value of ultrasonography in hydatid liver disease in children : a report on 42 cases (author's transl)]. J Radiol 61: 323-327.

48. Kumar S, Pandya S, Agrawal S, Lal A (2008) Laparoscopic management of genitourinary hydatid cyst disease. J Endourol 22: 1709-1713.

49. Tepetes K, Christodoulidis G, Spryridakis M, Hatzitheofilou K (2007) Large solitary retroperitoneal echinococcal cyst: a rare case report. World J Gastroenterol 13: 6101-6103.

50. Balik AA, Celebi F, Basglu M, Oren D, Yildirgan I, et al. (2001) Intraabdominal extrahepatic echinococcosis. Surg Today 31: 881-884.

51. Kumar S, Choudhary GR, Pushkarna A, Najjapa B, Vatasla Ht (2013) Percutaneous nephroscopic management of an isolated giant renal hydatid cyst guided by single-incision laparoscopy using conventional instruments: The Santosh-PGI technique. Asian J Endosc Surg 6: 342345.

52. Stojkovic M, Rosenberger K, Kauczor HU, Junghanss T, Hosch W (2012) Diagnosing and staging of cystic echinococcosis: how do CT and MRI perform in comparison to ultrasound? PLoS Negl Trop Dis 6: e1880.

53. Gogus O, Beduk Y, Topukcu Z (1991) Renal hydatid disease. Br J Urol 68 : 466-469.

54. Lightowlers, MW, Gottstein B (1995) Echinococcosis/hydatidosis: Antigens, immunological, and molecular diagnosis. CAB International, Wallingford, Oxon, UK.

55. Nasrieh MA, Abdel-Hafez SK (2004) Echinococcus granulosus in Jordan: assessment of various antigenic preparations for use in the serodiagnosis of surgically confirmed cases using enzyme immuno assays and the indirect haemagglutination test. Diagn Microbiol Infect Dis 48: 117-123.

56. Amin MU, Siddique K, Aftab PA (2009) Imaging features of renal hydatid cyst presenting with hydatiduria. J Radiol Case Rep 3: 6-11.

57. Al-Sherbiny MM, Farrag AA, Fayad MH, Makled MK, Tawfeek GM, et al. (2004) Application and assessment of a dipstick assay in the diagnosis of hydatidosis and trichinosis. Parasitol Res 93: 87-95.

58. Rott MB, Fernandez V, Farias S, Ceni J, Ferreira HB, et al. (2000) Comparative analysis of two different subunits of antigen $B$ from Echinococcus granulosus: gene sequences, expression in Escherichia coli and serological evaluation. Acta Trop 75: 331-340.

59. Virginio VG, Hernandez A, Rott MB, Monteiro KM, Zandonai AF, et al. (2003) A set of recombinant antigens from Echinococcus granulosus with potential for use in the immunodiagnosis of human cystic hydatid disease. Clin Exp Immunol 132: 309-315.

60. Feki W, Ghozzi S, Khiari R, Ghorbel J, Elarbi H, et al. (2008) Multiple unusual locations of hydatid cysts including bladder, psoas muscle and liver. Parasitol Int 57: 83-86.

61. Rahemtulla A, Bryceson AD, McManus DP, Ellis DS (1987) Albendazole in the treatment of hydatid disease. J R Soc Med 80: 119-120.

62. Horton RJ (1989) Chemotherapy of Echinococcus infection in man with albendazole. Trans R Soc Trop Med Hyg 83: 97-102.

63. Morris DL (1989) Albendazole treatment of hydatid disease--follow-up at 5 years. Trop Doct 19: 179-180.

64. Goel MC1, Agarwal MR, Misra A (1995) Percutaneous drainage of renal hydatid cyst: early results and follow-up. Br J Urol 75: 724-728.

65. Arif SH, Shams-Ul-Bari, Wani NA, Zargar SA, Wani MA, et al. (2008) Albendazole as an adjuvant to the standard surgical management of hydatid cyst liver. Int J Surg 6: 448-451.

66. Von Sinner WN, Hellstrom M, Kagevi I, Norlen BJ (1993) Hydatid disease of the urinary tract. J Urol 149: 577-580.

67. Horchani A, Nouira Y, Kbaier I, Attyaoui F, Zribi AS (2000) Hydatid cyst of the kidney. A report of 147 controlled cases. Eur Urol 38: 461-467.

68. Adewunmi OA, Basilingappa HM (2004) Primary ovarian hydatid disease in the Kingdom of Saudi Arabia. Saudi Med J 25: 1697-1700.

69. Zayed AM, Abdel-Rahman AH (2005) Isolated hydatid cyst of the kidney: diagnosis and surgical treatment. Arab J Urol 3: 6-12.

70. Vargas-Serrano B, Ferreiro-Arguelles C, Rodriguez-Romero R, Marcos del Rio N (1997) Imaging findings in renal hydatid disease. Eur Radiol 7: 548-551. 
Page 8 of 8

71. Hota D, Pujari S, Choudhuri S, Panda S (2015) Isolated Renal Hydatidosis Presenting as Renal Mass: A Diagnostic Dilemma. Urol Case Rep 3: 103-105.

72. Bret PM, Fond A, Bretagnolle M, Valette PJ, Thiesse P, et al. (1988) Percutaneous aspiration and drainage of hydatid cysts in the liver. Radiology 168: 617-620.

73. Ben Adballah R, Hajri M, Aoun K, Ayed M (2000) [Retrovesical and retroperitoneal extrarenal hydatid cyst: descriptive study of 9 cases]. Prog Urol 10: 424-431.

74. Bennani S, el Mrini M, Raji A, Méziane F, Benjelloun S (1992) [Isolated retrovesical and retroperitoneal hydatid cysts. 5 case reports]. Ann Urol (Paris) 26: 344-349.

75. Amar J, Garnier J, Faraj A, Taobane H, Aovame H, et al. (1983) [Isolated retroperitoneal hydatid cyst. Apropos of 2 new cases]. J Urol (Paris) 89: 147-152.

76. Aggarwal S, Bansal A (2014) Laparoscopic management of renal hydatid cyst. JSLS 18: 361-366.

77. Shah KJ, Ganpule AP, Desai MR (2009) Isolated renal hydatid cyst managed by laparoscopic transperitoneal nephrectomy. Indian J Urol 25 531-533.

78. Neumayr A, Troia G, de Bernardis C, Tamarozzi F, Goblirsch S, et al. (2011) Justified concern or exaggerated fear: the risk of anaphylaxis in percutaneous treatment of cystic echinococcosis-a systematic literature review. PLoS Negl Trop Dis 5: e1154.

79. Chipde SS, Yadav A, Ranjan P, Prakash A, Kapoor R (2012) Total laparoscopic management of a large renal hydatid cyst by using hydatid trocar cannula system. Journal of Surgical Technique and Case Report 4: $32-35$.

80. Ozden E, Bostanci Y, Mercimek MN, Yakupoglu YK, Yilmaz AF, et al. (2011) Renal hydatid cyst treatment: Retroperitoneoscopic "closed cyst" pericystectomy. International Journal of Urology 18: 237-239.

81. Zmerli S, Ayed M, Horchani A, Chami I, El Ouakdi M, et al. (2001) Hydatid cyst of the kidney: diagnosis and treatment. World J Surg 25: 68-74.

82. Caglayan K, Celik A, Koc A, Kutluk AC, Altinli E, et al. (2010) Unusual locations of hydatid disease: diagnostic and surgical management of a case series. Surg Infect (Larchmt) 11: 349-353.

83. Tscholl R, Ausfeld R (1985) Renal replantation (orthotopic autotransplantation) for echinococcosis of the kidney. J Urol 133: 456-457.

84. Zmerli S, Ayed M, Horchani A, Chami I, El Ouakdi M, et al. (2001) Hydatid cyst of the kidney: diagnosis and treatment. World J Surg 25: 68-74.

85. Goel MC, Agarwal MR, Misra A (1995) Percutaneous drainage of renal hydatid cyst: early results and follow-up. Br J Urol 75: 724-728.

86. Foster DG (1966) Adrenal cysts. Review of literature and report of case. Arch Surg 92: 131-143.

87. Yeniyol CO, Minareci S, Ayder AR (2000) Primary cyst hydatid of adrenal: a case report. Int Urol Nephrol 32: 227-229.

88. Bedioui H, Jouini M, Nouira K, Bouzid T, Kacem M, et al. (2005) [Primary hydatid cyst of adrenal gland. Report of two cases]. Ann Chir 130: 104-107.

89. Schoretsanitis G, de Bree E, Melissas J, Tsiftsis D (1998) Primary hydatid cyst of the adrenal gland. Scand J Urol Nephrol 32: 51-53.

90. Baraket O, Zribi R, Berriche A, Chokki A (2010) [Primary hydatid cyst of the adrenal gland in a patient with situs inversus. A one-case report]. Bull Soc Pathol Exot 103: 313-316.
91. Dede S, Dede H, Caliskan E, Demir B (2002) Recurrent pelvic hydatid cyst obstructing labor, with a concomitant hepatic primary. A case report. J Reprod Med 47: 164-166.

92. Cattorini L, Trastulli S, Milani D, Cirocchi R, Giovannelli G, et al. (2011) Ovarian hydatid cyst: A case report. Int J Surg Case Rep 2: 100-102.

93. Bozkurt M, Bozkurt DK, Çil AS, Karaman M (2012) Primary ovarian and pararectal hydatid cysts mimicking pelvic endometriosis. Acta Med Iran 50: 839-842.

94. Thakare PY (2014) Hydatid cysts in a pregnant uterus. J Obstet Gynaecol India 64: 215-217.

95. Rashid SQ (2011) Primary and solitary uterine hydatid cyst: A most unusual site. Journal of Medical Ultrasound 19: 57-60.

96. Bickers WM (1970) Hydatid disease of the female pelvis. Am J Obstet Gynecol 107: 477-483.

97. Bhattacharya A, Saha R, Mitra S, Nayak P (2013) Primary hydatid cyst of broad ligament. Trop Parasitol 3: 155-157.

98. Subramaniam B, Abrol N, Kumar R (2013) Laparoscopic Palaniveluhydatid-system aided management of retrovesical hydatid cyst. Indian J Urol 29: 59-60.

99. Dogra P, Javeli T, Saini A, Sharma S, Gupta N (2010) Isolated retrovesicalhydatid cyst [Internet]. Available from: http://www.bjui.org/ ContentFullitem.aspx?id=546.

100. Rao MS, Bapna BC, Shrikhande VV, Sharma SK, Rajendran LJ, et al. (1979) Obstructive azoospermia due to retrovesical hydatid cyst. Fertil Steril 32: 706-707.

101. Horchani A, Nouira Y, Chtourou M, Kacem M, Ben Safta Z (2001) Retrovesical hydatid disease: a clinical study of 27 cases. Eur Urol 40: 655-660.

102. Gorgen H, Api M, Cetin A1 (2009) Primary adnexial hydatid cyst mimicking ovarian tumor. J Turk Ger Gynecol Assoc 10: 232-234.

103. Sallami S, Nouira Y, Rhouma SB, Tanguour M, Cherif K, et al. (2010) Endoscopic treatment of a primary prostatic hydatid cyst: a mini-invasive therapeutic approach. Urol J 7: 270-274.

104. El-Kappany HA, El-Nahas AR, El-Nahas HA (2005) Laparoscopic excision of prostatic hydatid cyst: case report and review of literature. J Endourol 19: 290-294.

105. Bouchikhi AA, Lamrani YA, Tazi MF, Mellas S, Elammmari J, et al. (2013) Unilateral primitive hydatid cyst with surgical resection of the scrotum: a case report. J Med Case Rep 7: 109.

106. Singh B, Wani AA, Ganai AA, Singh M, Baba K (2001) Hydatid cyst of testis: An unusual presentation of hydatid disease - Case report and review of literature. Indian J Urol 18: 94-96.

107. Kumar PV, Jahanshahi S (1987) Hydatid cyst of testis: a case report. J Urol 137: 511-512.

108. Saglam M, Tasar M, Bulakbasi N, Tayfun C, Somuncu I (1998) TRUS, CT and MRI findings of hydatid disease of seminal vesicles. Eur Radiol 8: 933-935

109. Ahmadnia H, Kalantari MR, Ghanbarizadeh SR (2008) Why testes are resistant to hydatidosis: Is blood-testis-barrier responsible for this resistance? Nigerian Journal of Parasitology 29: 84-87.

110. Khan RA, Wahab S, Chana RS, Fareed R (2010) Isolated retroperitoneal hydatid cyst in a child: a rare cause of acute scrotal swelling? J Pediatr Surg 45: 1717-1719.

111. Mushtaque M, Mir MF, Nazir P, Khan PS (2012) Primary isolated echinococcal cyst of the seminal vesicle: A rare case. Urol Ann 4: 122-125. 